\title{
Research on Shunde Food Culture and Transmission of
}

\section{Creative Industries}

\author{
Wei $\mathrm{Bi}^{\mathrm{a}}$ \\ ${ }^{1}$ Graduate School of Creative Industry Design, National Taiwan University of Art, Taipei, Taiwan, \\ China, 999079 \\ ${ }^{\mathrm{a}}$ email
}

Keywords: Shunde Food Culture, Shunde catering, Creative Industries

\begin{abstract}
Shunde food culture is the most characteristic local culture in Shunde area. It has a close relationship with the creative industries. This paper analyzes the connotation of Shunde food culture and the status of the catering industry in the creative industries and gives countermeasures and suggestions for the spread of creative industries in Shunde to provide some references for the relative researchers.
\end{abstract}

\section{Connotation of Shunde Food Culture}

Shunde is located in the Pearl River Delta, richly endowed by nature natural geographical conditions. Generations living in the rivers and lakes regions, people in Shunde reclaim Shunde into the prosperous fish and fruit town according to local conditions in the long-term production practice. Deep cultural heritage breeds elegant exquisite delicacy culture. Today, the Fengcheng famous delicacy has become one of the most can reflect the cultural characteristics of the famous brand of Shunde. Shunde food originated in the Qin and Han Dynasties flourished in the middle of the Qing Dynasty and is brilliant in today. This ancient land began active in South Vietnam since the Qin Dynasty ancestors. Shunde cuisine is an important component of Guangzhou cuisine, its development track and the Guangzhou cuisine is roughly the same. From the Ming Dynasty, Shunde on the creative use of the geographical advantages of the river, the implementation of advanced production methods, rich products. They are an important source of the south of the Five Ridges River, but also the achievements of the diet characteristics of Shunde people good at cooking the fish. Leisure farm vegetables diet has become a big fashion in Shunde. Most farm restaurant built on the side of the road traffic convenience, but built in the countryside or deep water pond. Even many cultivated garden nursery field flowers have also been transformed into rural farm style restaurants, cooking water contains a unique thick local flavor and natural flavor of the cooked vegetable farm, let the city people enjoy to return to pastoral fun Shunde, originally from the Home Dishes towards the market, such as the hometown of fish coarse material, refined, its selling point is one of the kind of family taste. Favorable geographical positions to speed up the prosperity of Shunde's economy, promote the development of food culture, and promote the exchange of cultural exchanges with all over the country. During the Ming and Qing Dynasties, active and developed overseas trade to enrich and enhance the Shunde cooking skills at home and abroad, a variety of cooking techniques widely absorbed, so that Guangdong can develop rapidly, forming the Shunde food in a unique style in the north and South Flavor furnace, mixing Chinese and Western features in one, become an independent school, in the major cuisine in the famous sea talent shows itself. Shunde people have the spirit of innovation, bold exploration, unremitting pursuit, the achievement 
of the prosperity of today's economic development. This spirit is also reflected in the continuous innovation and progress of food culture. For a long time, Shunde food absorbed other cuisine director in dishes of raw materials, color, shape, taste and cooking techniques and utensils, menus, in combination, excavation of the ancient Western-style food dishes and so on. They create a lot of new dishes, which pay attention to green, healthy ideas in order to meet the dietary and nutrition, balance requirements.

\section{Status of the Catering Industry in the Creative Industries}

Identity is the bottleneck of the catering culture industry in Shunde. At the level of government policy, the catering industry has not been regarded as an independent cultural industry. While dietary practitioners are limited by their own quality, many people do not understand what is called the cultural industry, but also do not think how many cultural food industry. This point, from the catering industry personnel composition can be seen, there are cooks, waiters, managers, etc., but there is no design personnel catering industry. Judging from the current situation, the diet culture is the content of other cultural industries. It can be film, publications, advertising, the content of the network, but also can be a travel experience project, it may be to participate in the health of the diet of the sports industry. There are a variety of publishing industry and food and nutrition related books. In some film and television works, food culture is just a beginning of the story. The consequences of this situation are: they cannot reflect the true face of food culture, in particular, cannot reflect the real needs of the catering industry. Visible diet culture, there are many can be refined, improve the space, which is the space of food culture and creativity. The catering culture in the tourism industry is displayed as a folk culture, which aims to serve the tourists' experience of folk custom. In these folk diet culture, there is a considerable part of the catering industry, there is no substantial help. Of course, there are some successful cases. They not only led to the catering industry the size of stores, but also led to the breeding and production base of special lobster sauce. The publishing industry with a recipe, diet culture and literature, academic periodicals, such as leisure, leisure and literature are basically for tourism or leisure city services, some recipes for catering service, the academic has the smallest proportion, is the basic research achievements of anthropology, folklore and history or health, relationship with the catering industry is not too close. Real food culture and creative industries can have the film and television industry, animation industry, the publishing industry a variety of operational practices, but its core should be for the catering industry chain services. In this view, the food culture and creative industries should include food activities planning, diet product design and development, to diet culture as the core of multimedia development. Judging from the current situation in Shunde, some people have begun to pay attention to the cultural and creative industries and cultural and creative industries, and actively put the ideas into practice.

\section{Transmission Strategies of Shunde Creative Industries Based on Food Culture}

Promote Recognition Degree of Shunde Food Culture. Shunde cuisine has a distinct personality, through the baptism of history and enduring, and with the development of the history of a series of classic dishes, reflecting the cultural characteristics of Shunde and the spirit of style. Shunde food after a hundred years of history baptism and increasingly showing a strong vitality, so we can build Shunde exquisite dishes, mining, sorting, sublimation, promotion of Shunde food culture, giving full play to the unique advantages of the food culture in Shunde. The comprehensive quality of catering practitioners directly determines its spread in the Shunde food culture in the 
control level, its essence, to its dregs. To establish and improve the professional training and education institutions of Shunde food culture is the most direct way to improve the catering practitioners. Professional training institutions to improve the local or the creation of the Shunde food culture courses in Colleges and universities, on the one hand to improve the professional quality and level of catering practitioners; on the other hand, is conducive to the popularization of public understanding of Shunde food culture understanding, lay a good theoretical foundation for the spread of food culture in Shunde. By the local catering industry organization led joint local gourmet restaurant folklorists and other relevant experts and representatives of the people, the depth of excavation of Shunde food culture and customs. We are in a wide variety of local diet in Shunde, the selection of a representative of the competitiveness of the characteristics of a variety of food, to create a symbol of Shunde food resources. We should focus on the promotion of these resources, which are the world delicacy to the brand, and leading role to the development of local food culture, in order to achieve development strategy. It can learn from the development experience of Sichuan food, such as the mention. Many people want to taste the local snacks attracted well-known brands. Shunde local delicacy is precisely the lack of well-known brands, to highlight the brand value of the iconic resources. It can play an important role in the development of media dissemination of food culture, which is conducive to show Shunde delicacy food features and the inheritance and promotion of food culture.

Improve Transmission Efficiency of Shunde Food Culture. We need to establish a culture of Shunde food culture communication environment, the formation of healthy and stable healthy ecosystem. Combined with the national cultural policy, the mainstream media, business support for information to complete the circulation of cultural communication ecosystem. To establish a cross administrative region of the food culture development mechanism, the integration of resources around the country, and the results of some resources have been clearly focused on the development of the project. Construction of accessible transportation network linking the various regions with the characteristics of Shunde folk attractions, the establishment of cultural ecological circle. Through the development of folk tourism, the economy and culture are closely integrated, the formation of cultural ecological circle. We set up a healthy exchange base in the new media, the use of more agile, widely, in a diverse range of public opinion, the complex of the moment, set the force of the people to create the Shunde food culture ecosystem". Government departments should formulate policies in accordance with the facts of Shunde, from the national culture, eating customs management, for the development of food culture industry in Shunde to provide the environment for the development of cultural industries, supervision and guidance. Specifically, it should continue to improve the cultural market and infrastructure construction, cultivate professional talents and strengthen the external. Most of the tourist routes to ignore the local traditional food mainly lack of focus on the exchange platform to showcase food culture. In this regard, the development mode of Taiwan area Chinese snacks is worth learning, the Taiwan area will become a successful restaurant delicacy to attract tourists are attracted to the characteristics of signs. Taiwan area of Taipei and Kaohsiung city is provided by means of this platform, night market and night market many characteristics of Taiwan traditional snacks delicacy to inheritance and development, and promote the communication of local food culture, promote the economic benefits. Led by the government planning and catering enterprises to participate in a delicacy platform, will disperse the catering delicacy and folk culture together to focus on the development, form a set of diet culture and leisure tourism as an integrated food culture business circle. They generate economies of scale, so that diners as long as the food business district to a turn, you can taste the traditional characteristics of Shunde food, feel the thick of water culture. 
Integrate Transmission Resources of Shunde Food Culture. On one hand, the festivals are the sources of information on the media; on the other hand, the media's agenda setting and guide the development of the festival activities. The media set the public agenda, and make it become the focus of audience attention. The media reported a positive opinion for the Shunde delicacy culture festival. During the festival, we guide the audience's attention and consideration by the media reports. They will eventually become the media audience festival activities of consumers. At the same time the festival activities in the activities of the participants may attract, through interpersonal communication from the audience to become disseminators of information. Events organized by the success or not, not only by the theme of the festival itself and other attractions, but also stimulate the media, the name of enterprises and celebrities. Festival is a general term for festivals and special events, through the planning, organization, the link of operation and management, and integrate into the respective regional culture and characteristics of resources, the participants bring sensory experience, promote local economic and social benefits of development, improve the image of the city, set up the industry brand, a short time to increase market population competitive aggregation activities and events of integrity characteristics of high impact. It has a very important role to attract young audiences. Festival event organizers can take full advantage of the new media strong interactive participation, through the form of the game to mobilize the enthusiasm of the participants to actively spread, so that participants complete the dissemination of information on the activities of the festival. In addition, the information releasing and forwarding of the micro-blog and WeChat can stimulate the audience's desire to obtain information of the festival and further expand the dissemination of information on the activities of the festival. Shunde food and beverage industry in order to achieve rapid development, the only way is to integrate the elements of innovation, adhere to the catering industry and creative industries closely. We chase the current popular food consumption theme, touch into the design concept of food and drink, to society like fashion groups of food consumption and the characteristics on the basis of development, has a distinct flavor of the times of diet products, not only to keep up with the trend of fashion, sometimes even to lead the new fashion trend. Customers in the food and beverage consumption, not only pay attention to the taste of the diet, pay more attention to the food and beverage agency of the scene and the environment. We should build today's food and beverage space which matches the current of time.

\section{Conclusion}

Food culture is an important part of the local culture in Shunde. It should be the focus of the development of the creative industries in Shunde. Currently, there have been some food cultural and creative activities and achievements in Shunde. However, these activities and achievements are not enough. We should strengthen the transmission of Shunde food culture to build the Shunde cultural and creative industries.

\section{References}

[1] Wang Hongmei, Journal of Sichuan Tourism College, Vol. 18 (2016) No 4, p.19-22

[2] He Ruilian, Culinary Science Journal of Yangzhou University, Vol. 4 (2007) No 4, p.4-6

[3] Zhu Xiaojing, Literature Education, Vol. 11 (2015) No 7, p.18-21

[4] Zhang Jianguo, Arts in China, Vol. 6 (2014) No 4, p.123-124 